\title{
A Proposed Model for Building Energy Lighting Simulation
}

\author{
Syed Rizwan Ali ${ }^{1{ }^{* *}}$, Laime Mahjdoubi², Azmat Khan ${ }^{1}$ \\ ${ }^{1}$ Department of the Computer Science, Bahria University Karachi Campus (BUKC), Pakistan \\ ${ }^{2}$ Department of the Build Environment, University of the West of England, United Kingdom
}

Copyright $(\subset 2015$ by authors, all rights reserved. Authors agree that this article remains permanently open access under the terms of the Creative Commons Attribution License 4.0 International License

\begin{abstract}
The use of building lighting simulation has increased in recent years, due to the growing demands of economic consequences from energy consumed by electricity in buildings. The building energy efficiency is of high priority in many countries of the world. This research investigates the important underlying issues affecting the effective use of one of the most powerful computational lighting simulation software, ECOTECT, to assist in the daylighting design of an actual building. The validation studies, which were carried out in the UWE in Bristol, U.K. revealed that ECOTECT can be used to predict the internal illuminance with a high degree of accuracy under overcast sky conditions. This is of particular concern for commercial and institutional buildings.
\end{abstract}

Keywords Validation, Accuracy, Lighting Simulation

\section{Introduction}

The study of daylighting has often been recognized as useful source of energy savings and visual comforts in building designs. Occupants expect good daylight in their working spaces. The quality and quantity of natural light entering a building depend on both internal and external factors Instant of artificial lighting.

According to [5], lighting simulation software is an attempt to provide an accurate simulation of a building design, thus it is perceptually, mathematically and logically correct. [5] [5] also recommended that a great number of lighting simulation software and tools have been developed in the last 10 years, due to availability of the many lighting simulation software in the built environment industry that makes ambiguity for the designers to select the right lighting simulation software.

According to [2], $50 \%$ to $75 \%$ energy combustion reduction not only for the embellishment design it would also be better for new buildings which is relative to 2000 levels, and only the $30 \%$ suitable involvement of the existing stock and also recommended that it could reduce the nation bill and be useful for the improvement of the environmental impact on climate change.

Due to a high demand all over the world to conserve energy and natural resources it is necessary to evaluate the performance of architectural design of the buildings though lighting simulation software before their actual construction. According to [6], in U.S lighting costs approximately $\$ 40$ billion per year and it consumes $25 \%$ electricity and U.S. department of energy EERE [9] suggests that U.S lighting cost is approximately $\$ 58$ billion per year and it consumes $22 \%$ electricity. The lighting simulation of a proposed building will help the architects in optimizing the design to minimize its energy requirements. It is critical to perform the lighting simulation of the building before its design gets finalized, as it will be impractical or in some cases impossible to make alterations in the building to make it more energy efficient after its construction.

U.S. department of energy EERE [9] suggests that by using simulation technologies in construction, buildings can reduce energy cost up to 50 percent.

\section{Why Lighting Simulation Software is Important}

The use of lighting simulation software has increased in recent years due to the growing demands in energy crises, renewable energy resources, sustainability, and health by using daylight in space rather than artificial lights in commercial or institutional space with windows or skylights [6].

Lighting simulation plays a vital role to improve energy performance quality in built environment. According to [8] Without assessing lighting simulation in them, buildings will be subject to the negative effects of daylights, whether or not they use its positive qualities because lighting effects may also be used to highlight changes in moods, atmosphere and it can be used for different purposes, by specifically focusing on its current operation and 
implementation into the design process. In doing so, the illumination design could not be operated or complete unless day lighting effects are addressed. Assessing day lights in building design is called 'useful day light illuminance' or 'UDI' [6] [11].

The lighting simulation in building design is a complicated process involving modeling and analytical skills, so the building practitioners and designer are often found to carry out the building energy analysis and comprehend the day lighting simulation results. [10] Suggests the government officials and the experienced lighting modelers are even also confused sometimes by a wide range of day lighting simulation software and feel uncertain about the validity and accuracy of the light energy calculation. These lighting simulation software's or tools are used by the 3D architectural simulation tools. And the key issues are as follows:

- Avoid in terms of cost, time, and effort

- Get more accurate results of building design lighting performance

- Sustainability issues

- Save energy

- Use more daylighting and reduce the use of artificial lighting

\subsection{Research Issues}

The current state of research moving towards building lighting simulation is driven by the ongoing development. [7] Suggests that the climate has influence in the building energy performance and its parameters like temperature on heating and cooling, wind speed and direction on space heating and ventilation, the solar radiation on cooling and lighting, hours of day lighting. The ability to analyze energy requirements accurately in new buildings at various design stages can help clients achieve optimization and meet the requirements laid down by local energy legislation.

Further increase in the demand for lighting simulation is too completed as new policies and regulations are coming up, such as the European Union (EU) directive on building energy performance. With increasing concern in this field, architectural industry is demanding more simulation and validation to be performed on buildings prior to construction, so as to better understand the building design and energy performance relationships.

\subsection{Aims \& Objectives of this Research}

\subsubsection{Aim:}

The main aim of this research is to determine the accuracy and reliability of lighting simulation software's in building design. Particularly it will investigate the claim made by ECOTECT lighting software.

\subsubsection{Objectives:}

- To evaluate the performance of ECOTECT lighting software
- To validate the software using experimental design

- To ascertain the approximation of the following lighting methods real life measurement

- To propose the future trends in lighting simulation software for building design and construction.

\subsection{Research Incentive}

This research is a contribution to the field of building energy simulation. As the lighting simulation demand increases continuously the need for accuracy in building design is also in high demand; by performing validation process this research will provide adequate cost effective solution to meet the high real time energy parameters.

\section{Proposed Methodology}

This research is interested in validating lighting simulation software which is commonly used in building design. The rational and important issues of lighting have an effect upon performance and contain economic consequences.

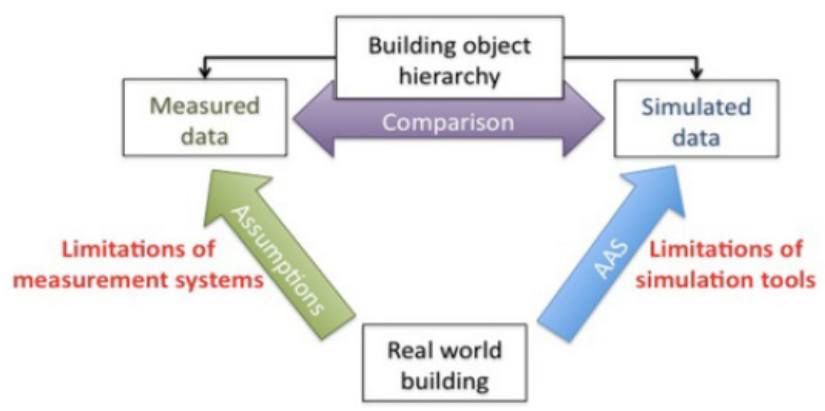

Figure 1. Overview of Concept

This study comprises of ECOTECT 3D architectural lighting simulation tools and is going to calculate the lighting performance in building design via a daylighting factor. The three rooms will be selected in University of West of the England [UWE]. Each room will be used to calculate five readings. The selections made on three different rooms are therefore:

- $\quad$ Room 1 [2p 50-51] big hall

- Room 2 medium [4q6] lecture room

- Room 3 small facility kitchen [3q65] room

Room 1 will be a big hall. Initially, the height and length of the walls, windows and doors will be measured. Secondly, different readings from five different places in the room will be obtained with the help of a Lux meter. The same procedure will be performed on Room 2 and Room 3. After acquiring the reading from different places in the University, this research will analyze what are the effects on effective use and the energy performance factors.

This research approaches these five readings from five different positions in three different rooms in the UWE. The readings will then be entered in the ECOTECT 3D 
architectural lighting simulation tools and see what effects on effective use of the lighting performance factors. And is the predicted value of daylighting parameters approximately same as the existing value of daylighting parameters? Do the validation process measures and address quality control of the building design and environmental software accuracy. This research project requires a swift solution by analyzing the problem in deep, thus finding the existing solution and finally suggesting an own optimized solution. To get the legitimacy on this project, the research will be an experimental evaluation. These experiments will be based on the building lighting simulation studies. The lighting simulation will be carried out on ECOTECT simulation software package, and the results will be discussed to explore the validity of the accuracy in building lighting simulation. So it is clear that empirical (IEA validation suite) methodology has been selected for this research. The IEA empirical validation package was developed in 1994; it contains detailed information for between two to ten days experiments. Those experiments are using three highly monitored test rooms, the IEA validation package suite mainly used in validating building energy software [3].

\subsection{Validity of the Approach}

Validity reflects that how accurately the research findings represent the real world situation [4]. [1] Suggest '...validity refers to the general correctness of the fact or evidence used in understanding and studying behavior ...' Because of the nature of research problem, it would be difficult to clearly specify the validity of the research. But based on the fact that the research will be done by analyzing and observing the existing software, it could be argued that the proposed research will produce valid results.

\section{Conclusions}

This research attempts to identify a few current and ongoing problems of the building energy simulation tools, and suggests possible solutions and methods on how to incorporate tools into the design process in order to enhance and optimize the energy efficiency in built environment. Energy efficient building demands that architects adopt a qualitative building energy simulation tool to review energy impact of building design options even if it's early design stage going to be constructed.

However, use and availability of such sophisticated building design tools in design practices is currently limited. Alternatively a qualitatively resultant design tool could serve to predict energy savings thus help architects in making informed design decisions.

\section{Acknowledgements}

I am very grateful to Dr. Prof Lamine Mahdjoubi from UWE, UK for his appropriate and constructive suggestions to improve this research and also Dr. Humera Farooq HoD CS Dept. Bahria University Karachi Campus for her support.

\section{REFERENCES}

[1] Adams, G.R. \& Schvaneveldt, J.D, (1985) Understanding Research Methods. Longman Inc, New York, USA.

[2] Clark's, JA. (2001) Energy Simulation in Building Design. 2nd Edition. Oxford, Boston: Butterworth Heinemann.

[3] Crawley, D. B (2001) Testing and Validating types. Testing and Validating of a New Building Energy Simulation Program. In Seventh International IBPSA Conference, Brazil 131 August 2001. UAS: Learned information, pp 353 to 355

[4] Collis, J. \& Hussey, R, (2003) Business Research: A practical guide for undergraduate and postgraduate students, 2nd Ed. Palgrave MacMillan, London, UK.

[5] Edward Yan-Yung Ng, Lam Khee Poh, Wu Wei, Takehiko Nagakura, (2001). Elsevier Science, Automation in Construction. Advanced lighting simulation in architectural design. pp 365-379

[6] Gary, S. (2002) US lighting cost per year In: W, John ed. Architectural Lighting Design. 2nd Edition. New York. USA: 2002. pp1.

[7] Guan L, Yang J, Bell JM. (2007) Cross-correlation between weather data variables in Australia. In: Building and Environment. pp42 -1054-70.

[8] Turner, J (1994). Lighting an Introduction to Light, Lighting and Light use. London: B.T. Batsford Ltd.

[9] U.S. department of energy (2015). US lighting cost and efficient building percentage reduction [online]. EERE (Energy Efficiency and Renewable Energy)Available from:http://wwwl.eere.energy.gov/buildings/betterbuildings/ accelerators/lighting.html [Accessed: 12 August, 2015]

[10] Sam. C. M. Hui., (2003). Building energy efficiency standards in Hong Kong and mainland China, In: ACEEE Summer Study on Energy Efficiency in Buildings, 20-25 August, Pacific Grove, California.

[11] Bristol, U. K. "The Comparison Study Between UK Daylighting Simulation-Malaysia Daylighting Simulations Due To Overcast Sky

Conditions.",Availablefrom:http://www.jmest.org/wp-conten t/uploads/JMESTN42350862.pdf [Accessed by 15 July 2015]. 